\title{
Investigation on creep age forming of AA2219 stiffened structures
}

\author{
Haoliang Yang ${ }^{1, a}$, Lidong Liu ${ }^{1}$, Haipeng Chen ${ }^{1}$, Liliang Wang ${ }^{2}$, and Tong Qin ${ }^{1}$ \\ ${ }^{1}$ Beijing Institute of Astronautical Systems Engineering, China \\ ${ }^{2}$ Imperial College London, UK
}

\begin{abstract}
The research described in this paper is a study of CAF a 2219 aluminium alloy, which is used for fabricating the isogrid structure for fuel tanks of launch vehicles. The main aim of the research is to develop a small scale CAF test rig, which was designed to analyse the springback behaviour from CAF. The main objective of the experiment was to investigate the potential proposals of creep age forming stiffened structures. Based on the results of the experiment, a potential CAF process for forming $1 / 3$ pieces of an isogrid cylindrical assembly was proposed.
\end{abstract}

\section{Introduction}

Weight saving is of great importance in designing and fabricating aerospace structures because of the high cost of each kilogram of payload [1, 2]. The launch vehicles body itself generally demand for lightweight designs. Isogrid structures meet the needs of lightweight with high strength to weight ratios in launch vehicle structures. Aircraft fuselage, interstates, shrouds, orbital workshop interiors and launch vehicle fuel tanks are the main applications of these structures in airspace and aerospace industry [3-5]. These structures are characterized by a shell structure supported by a lattice pattern of stiffeners on either the inner or outer sides of the shell. It employs an array of equilateral triangle cut-outs to increase the stiffness per weight of a structure [6]. The concept of implementation of isogrid structures began in the early 1960s using aluminium structures and development continues today with focusing on optimizing stiffening patterns to further decreasing the weights [7]. The material used for manufacturing isogrid structures of fuel tanks is aluminium alloy 2219, which has a unique combination of properties such as its good ability to weld, high strength to weight ratio and superior cryogenic properties [8-10].

The isogrid structure has been successfully employed for the manufacture to fuel tanks of launch vehicle of LM Family developed by China Aerospace Corporation [11]. Figure 1 illustrates the assembly of the AA2219 isogrid structure for the fuel tanks of LM-2F launch vehicles.

Figure 2 reviews the current manufacturing sequences involved in producing the cylindrical fuel tanks of launch vehicles $[12,13]$. Firstly, the isogrid structures are typically fabricated by numerically controlled CNC machining operation on an AA2219-T87 flat panel. Next, the machined isogrid panels

\footnotetext{
${ }^{\text {a }}$ Corresponding author: haoliang.yang@foxmail.com
}

This is an Open Access article distributed under the terms of the Creative Commons Attribution License 4.0, which permits unrestricted use, distribution, and reproduction in any medium, provided the original work is properly cited. 


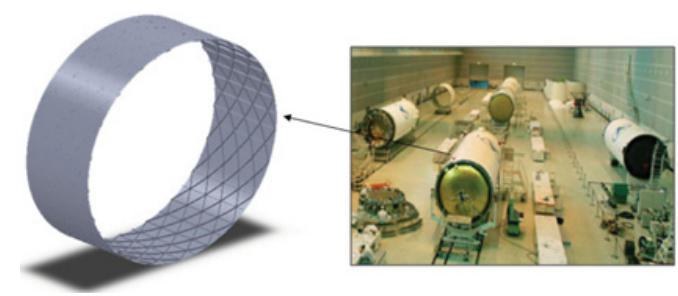

Figure 1. AA2219 isogrid stiffened structures for fuel tanks of launch vehicles.
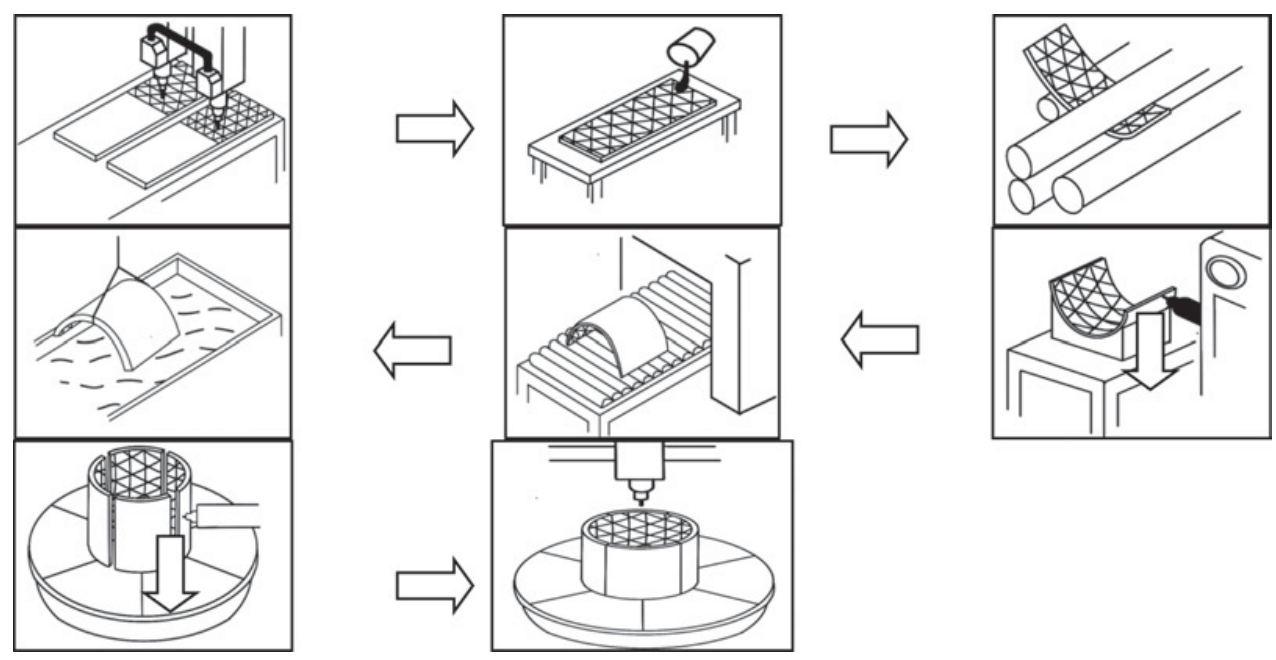

Figure 2. Roll forming sequence for isogrid stiffened structures.

are rolled after the machined-out pockets filled with a low melting wax. This filler material stabilizes the isogrid ribs, evenly distributing the forming/bending force throughout the whole structure during rolling. Rolling process without a filler material may result in irregular skin and buckling of the ribs. After rolling process, the wax is melted out at $60^{\circ} \mathrm{C}$ and the isogrid panel is cleaned in the water tank with the trimming of longitudinal edges thereafter. Finally, a cylindrical isogrid panel can be obtained by joining four pieces of individual formed isogrid panels via friction stir welding (FSW). Excess materials at the lateral edges are machined off.

\section{Creep age forming in forming isogrid structures}

Creep age forming is now widely applied in aircraft industry. For example, both the upper and lower wing skins of B-1B' Long Range Combat Aircraft of the USA are produced using CAF [14]. "Bennetts Associates" has worked with Airbus on the development of CAF for producing the wing skin for the latest A380 airplane, using AA7055 alloy (Fig. 2.1(a)). The length of the wing skin is $33 \mathrm{~m}$, its widest section is $2.8 \mathrm{~m}$, and it has a double curvature aerodynamic surface. Its thickness varies from 3 to $28 \mathrm{~mm}[15,16]$. STADCO, USA also developed one of the largest creep age-forming tools to manufacture Gulfstream G-5 upper and lower wing skin [16, 17].

Shaping the specified structures using CAF is based on the stress relaxation behaviour due to creep, which occurs during the artificial ageing process. However, due to the time and temperature restrictions in $\mathrm{CAF}$ being specified to achieve a particular requirement of mechanical properties, the residual stress 


\section{ICNFT 2015}

Stage 1: Isogrid panel prior to CAF

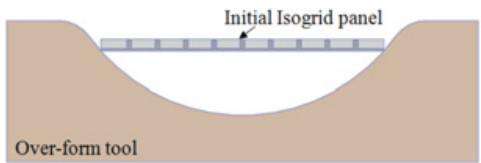

Stage 2: Isogrid panel reconfigured to the tool shape by either autoclave method or mechanical method
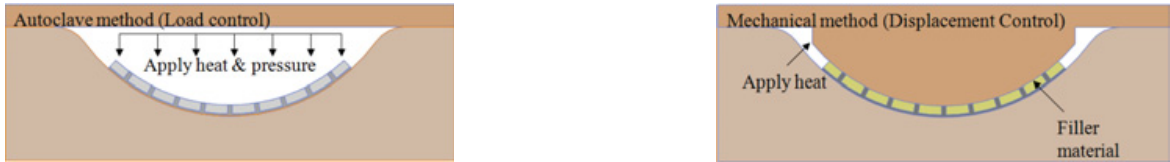

Stage 3: Final creep age-formed isogrid panel after springback

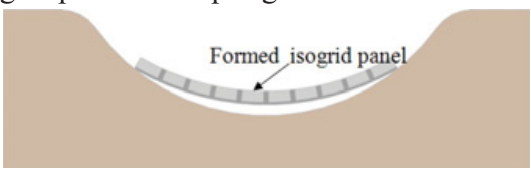

Figure 3. Illustrations of the three stages in the CAF process for forming isogrid panel.

could not be fully released during CAF, and thus springback takes place. Springback is one of the main drawbacks of $\mathrm{CAF}$, which may lead to the formed structure being out of tolerance, introducing problems during assembly or installation. The common methodology to compensate springback by industry relies on trial and error, recursively modifying the tool shape until the formed structure springbacks to the required shape. Practically, the methodology above is costly, laborious and time consuming. It is therefore significant to develop an integrated system to predict the springback behaviour of the formed structures via numerical simulation, and subsequently modify the tool shape to compensate springback [18-23]. To creep-age form the isogrid panel, two types of loading methods can be employed, as shown in Fig. 3. For autoclave forming condition, only a bottom die is required for manufacturing ultra large components. However, a pressurized autoclave, though adds significant cost. While for mechanical forming condition, this is similar to the traditional sheet metal forming process, e.g. stamping. The furnace used for ageing would not lead to significant extra cost, as an ageing furnace would be required to increase alloy mechanical properties in any type of processing route. However, an upper die would be heavy, difficult to handle and requires extra cost for tool machining. In addition, high temperature resist material should be used to fill into the isogrid structures to stabilize the isogrid rib stiffeners, in order to distribute the forming/bending force through the compression/bending process $[24,25]$.

\section{Experiments on forming isogrid structures}

An end clamp device was designed and used to creep age form a stiffened panel structure. The experiment consisted of three stages: in the first stage, an end clamp device, capable of generating a constant radius profile, was employed to deflect the specimen into the expected shape. In this stage, PTFE filler material was used to fill the machined-out pockets in the panel to avoid the contact force being compressed directly on the ribs. In the second stage, the compressed specimen, together with the end clamp device, was put into a closed furnace at $175^{\circ} \mathrm{C}$ for duration of up to 18 hours. In the last stage, after the end clamp device was cooled down to the room temperature, the upper die device was removed and the specimen springed back.

The specimens were machined into an isogrid stiffened panel. A flat $4.5 \mathrm{~mm}$ thick panel was also employed in the experiment. All the specimens were solution heat-treated and water quenched prior to the test. The dimensions of the four types of workpiece are shown in Fig. 4. 

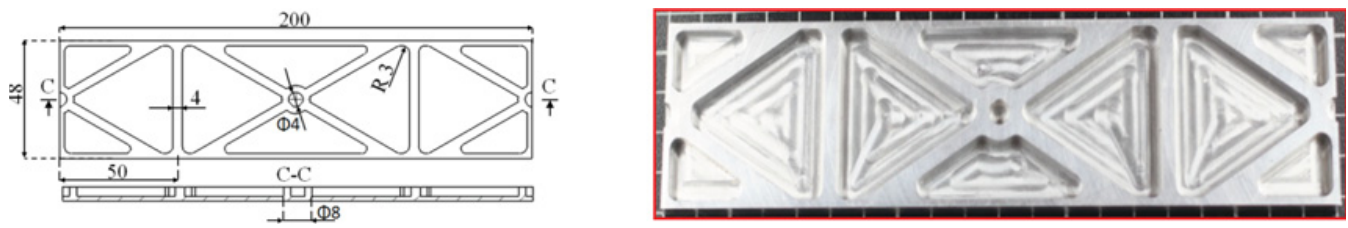

Figure 4. Illustration of the stiffened panels. (all dimensions in $\mathrm{mm}$ ).

(a)

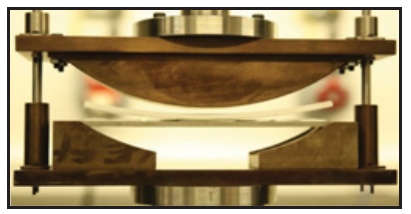

(c)

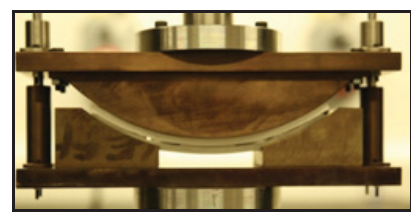

(e)

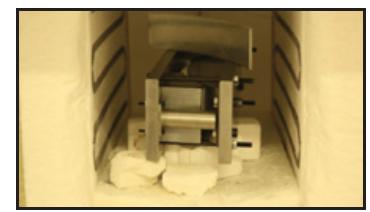

(b)

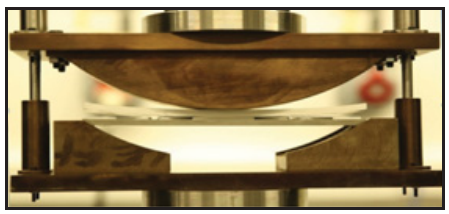

(d)

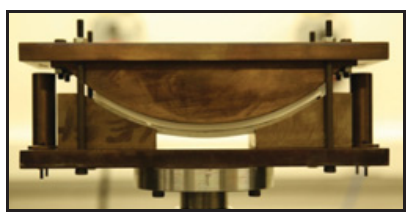

(f)

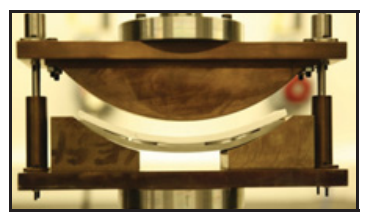

Figure 5. Pictorial illustrations of the experimental procedures.

The initial workpiece was placed, centred, and properly aligned on the two clamps. Some markings were used to assist the alignment. $6 \mathrm{~mm}$ thick trimmed PTFE filler material was used to fill the machinedout pockets of the stiffened panels. Another $6 \mathrm{~mm}$ thick plane PTFE material was placed on the top surface of the trimmed PTFE filler material to transfer the compression force (Fig. 5(a)). The cylindrical die was installed on the Lloyd 5588 material testing machine; the displacement control model was used. Both the cross head speed and displacement were pre-set. The cylindrical die was lowered using a sensitive control until the $6 \mathrm{~mm}$ thick plane PTFE started to transfer the compression force onto the tested workpiece; an obvious positive loading change was the indicator used to confirm that the compression force was beginning to be transferred (Fig. 5(b)). The displacement and load indicator was then zeroed. The cross head was allowed to travel down at a constant speed so as to press down the cylindrical die and consequently compress the workpiece to the target displacement, i.e. by $38 \mathrm{~mm}$ in all the stiffened panels (Fig. 5(c)). Once the target distance was achieved, the cross head was stopped. Four locking bolts were applied to tighten the end clamp device in order to hold the workpiece in place. A value of around zero displayed on the indicator was taken to mean that the end clamp device was fully tightened (Fig. 5(d)). The end clamp device was then removed from the Lloyds 5588 material testing machine and the entire end clamp device associated with the compressed workpiece was put into a closed fan furnace (Fig. 5(e)). The temperature of the furnace was kept constant at $175^{\circ} \mathrm{C}$ for 18 hours to allow age hardening and stress relaxation to take place. After 18 hours, the furnace was 

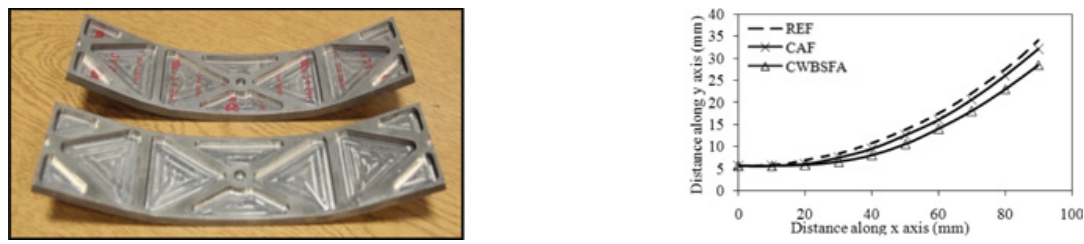

Figure 6. Illustration of (i) the visual profile and (ii) comparison of the profile between CAF and comparable workpieces.

opened. The entire rig together with the held, deformed, workpiece was removed from the furnace. After cooling to room temperature (up to 3 hours), the locking bolts were removed from the end clamp device. The workpiece was then allowed to springback (Fig. 5(f)). As well as forming these CAF workpieces, parallel experiments were also carried out to form workpieces directly without creep forming.

Figure 6 shows a visual profile and a plotted comparison of the CAF and comparable workpieces. The outer profile of the half-deformed workpiece was plotted on coordinate paper. In Fig. 6, REF, which equals $156 \mathrm{~mm}$, refers to the outer profile of the deformed workpiece without springback. From Fig. 6, two conclusions can be deduced:

A stiffened workpiece with a curvilinear profile could be obtained using a mechanical creep age forming method with the application of PTFE material filling in the machined-out pockets.

For the same compression procedures, the springback experienced by the CAF workpieces was less than that for the comparable workpieces.

\section{Suggestions of mechanical creep age forming for isogrid panels}

Base on the experimental work. Suggestions of mechanical creep age forming for isogrid panels was given here. Firstly, the CNC machining operation is conducted on an AA2219-T4 isogrid panel. When the section being machined has been completed, it is filled with PTFE material, which is able to deform with the isogrid panel up to a temperature of $260^{\circ} \mathrm{C}$. Next, the isogrid panel filled with PTFE material is compressed to the desired curvature using a compression die tool. Once the panel is in full contact with the lower die, the upper die is stopped and locked into position using bolts. Thereafter, the entire system is put into a closed fan furnace at a temperature of $175^{\circ} \mathrm{C}$. After 18 hours, the entire system is removed from the furnace and cooling takes place. After the system has cooled down to room temperature, the upper die is removed and a curved isogrid panel is obtained. The filler material can then be removed from the isogrid panel and the leading and trailing edges of the panel are trimmed. Finally, a cylindrical structure can be obtained by assembling three pieces of single formed isogrid panels via friction stir welding.

Figure 7 represents the mechanical-based CAF manufacturing sequences involved in producing cylindrical isogrid structures.

\section{Conclusion}

The present research is the preliminary work to investigate the CAF features of aluminium alloy 2219 and investigation of the related forming work for CAF AA2219 isogrid structures. A CAF equipment should be designed for forming $1 / 3$ pieces isogrid cylindrical structure to further validate the novel CAF process for forming isogrid structure in the industrial application. 

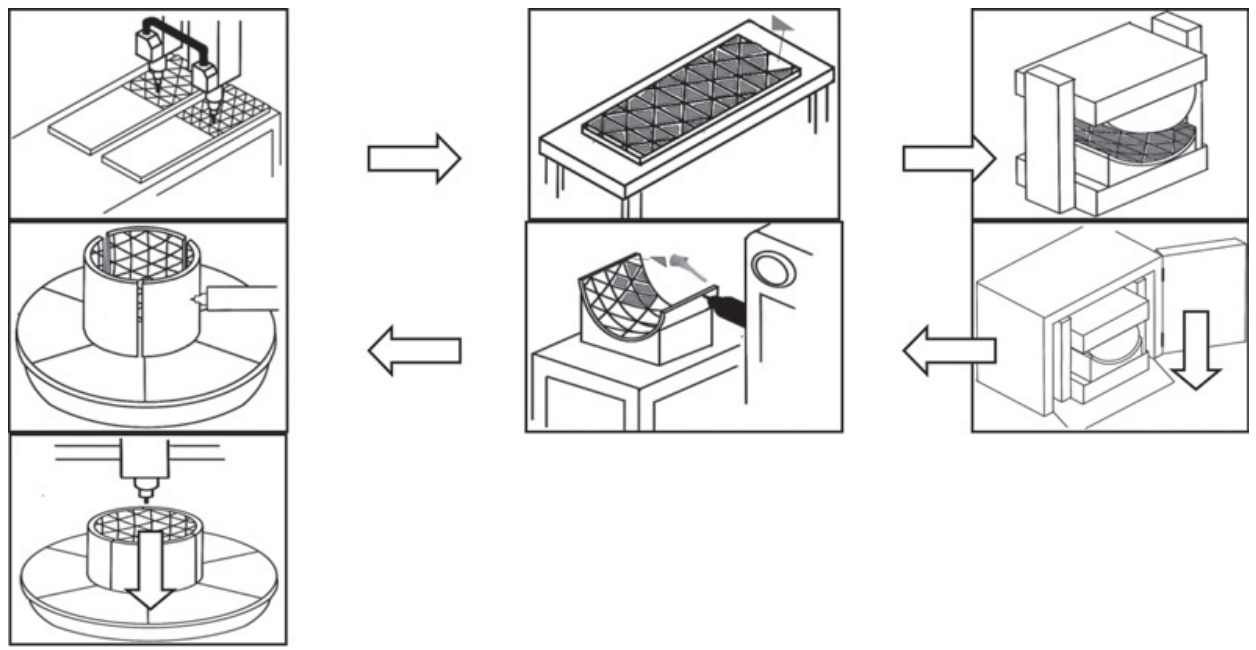

Figure 7. A schematic illustration of the CAF process for forming $1 / 3$ pieces for isogrid cylindrical assembly by bending and forming.

\section{References}

[1] H. Lee, Integration of cost modeling and business simulation into conceptual launch vehicle design p. 97-111 (1997)

[2] L. Pranke, Human spaceflight: mission analysis and design (2000)

[3] J. Hopkins, International reference guide to space launch systems (1999)

[4] T. Meink. Advanced grid stiffened structures for the next generation of launch vehicles (Aerospace Conference, 1997)

[5] V Díaz, E. Olmo, and M. Frövel. Design \& development of advanced composite isogrid structural solutions for primary structures of future reusable launch vehicle (1989)

[6] D. Glass and H. Belvin. Airframe technology development for next generation launch vehicles. in Prepared for the 55th InternationalAstronautical Congress, Vancouver, Canada (2004)

[7] M. Hilburger, Design and Analysis of Subscale and Full-Scale Buckling Critical Cylinders for Launch Vehicle Technology Development NASA REPORT (2012)

[8] K. Masubuchi, Integration of NASA-sponsored studies on aluminum welding (1972)

[9] G. Narayana, Fracture behaviour of aluminium alloy 2219-T87 welded plates. Science and Technology of Welding \& Joining 9: p. 121-130 (2004)

[10] I. Polmear, Recent developments in light alloys. JIM, Materials Transactions 37: p. 12-31 (1996)

[11] Y. Jia, Y. A Series of Chang-Zheng Rockets' Space Launch Number of Times Amount to 100 by the Thirteenth of September. Spacecraft Recovery \& Remote Sensing 4: p. 20-27 (2006)

[12] V. Vasiliev, V. Barynin, and A. Rasin, Anisogrid lattice structures-survey of development and application. Composite structures 54: p. 361-370 (2001)

[13] R. Meyer, O. Harwood, and J. Orlando, Isogrid design handbook (1973)

[14] M. Holman, Autoclave age forming large aluminum aircraft panels. Journal of Mechanical Working Technology 20: p. 477-488 (1989)

[15] F. Eberl, Ageformable panels for commercial aircraft. Proceedings of the Institution of Mechanical Engineers, Part G: Journal of Aerospace Engineering 222: p. 873-886 (2008)

[16] P. Xue, T. Yu, and E. Chu, An energy approach for predicting springback of metal sheets after double-curvature forming, Part I: axisymmetric stamping. International journal of mechanical sciences 43: p. 1893-1914 (2001) 


\section{ICNFT 2015}

[17] L. Zhan, J. Lin, and T. Dean, A review of the development of creep age forming: Experimentation, modelling and applications International Journal of Machine Tools and Manufacture 51: p. 1-17 (2011)

[18] T. Meinders, Numerical product design: springback prediction, compensation and optimization, International Journal of Machine Tools and Manufacture 48: p. 499-514 (2008)

[19] L. Li, Numerical simulations on reducing the unloading springback with multi-step multi-point forming technology, The International Journal of Advanced Manufacturing Technology 48: p. 45-61 (2010)

[20] J. Liao, A new springback compensation method for sheet metal bendingbased on curvature correction, Advanced Materials Research, 97: p. 130-134 (2010)

[21] Cafuta, G., N. Mole, and B. Štok, An enhanced displacement adjustment method: Springback and thinning compensation, Materials \& Design (2012)

[22] K. Chun, The 8th international conference and workshop on numerical simulation of $3 \mathrm{~d}$ sheet metal forming processes (2012)

[23] H. Tan, J. Zhu, Simulation and Springback Prediction of IntegralPanel with High Ribs in Age Forming. Applied Mechanics and Materials, 152: p.135-139 (2012)

[24] N. Abuelfoutouh, A. Gad, Finite Element Analysis for Satellite Structures: Applications to Their Design, Manufacture and Testing (2013)

[25] Lu. M., Comparative study of tribological properties of different fibers reinforced PTFE/PEEK composites at elevated temperatures. Tribology Transactions, 53: p. 189-194 (2010) 